\title{
Self-directed Learning Strategy, Learning Flow, Teaching Presence, and Learning Satisfaction of Nursing College Students in Non-face- to-face Online Classes
}

\author{
Sook Kang \\ Assistant Professor, Chosun Nursing College, South Korea \\ skang@cnc.ac.kr
}

\begin{abstract}
The purpose of this study is to analyze relationship between self-directed learning strategy, learning flow, teaching presence, and learning satisfaction of nursing college students who participated in non-face-to-face online classes. To this end, it intends to find out effective online teaching methods and provide the necessary basic data for improving learning satisfaction. A total of 110 students of nursing college in $G$ city were the subjects of this study and surveyed for research in a self-reporting form May 5 to May 30, 2020. Data were analyzed using $t$-tests, Pearson's correlations coefficients, and a stepwise multiple regression with the IBM SPSS Statistics 25.0 program. Self-directed learning strategy averaged $4.08( \pm 0.56)$, learning flow averaged $3.28( \pm 0.74)$, teaching presence averaged $4.15( \pm 0.64)$, and learning satisfaction $4.18( \pm 0.75)$. Learning satisfaction showed significant positive correlations with self-directed learning strategy $(r=.55, p<.001)$, learning flow $(r=.62, p<.001)$ and teaching presence $(r=.86$, $p<.001)$. Teaching presence, which accounted for $74 \%$ of the variance, was a significant predictor of learning satisfaction among nursing college students. Therefore, in order to improve the learning satisfaction of nursing college students in online classes, a variety of methods should be explored and applied to enhance teaching presence. This study can be used to establish an online learning management system to improve learning satisfaction.
\end{abstract}

Keywords: Self-directed learning strategy, Learning flow, Teaching presence, Learning satisfaction

\section{Introduction}

The coronavirus disease (COVID-19) pandemic has not only impacted day-to-day life but also education. Many universities in Korea started the digital and online education across campuses and face-to-face education. This resulted to staff and students having to adapt to the rapid digitalization of both the curriculum as well as ways of teaching Error! Reference source not found.

Online learning (OL) can be termed as a tool that makes the teaching-learning process more student-centered, more innovative, and even more flexible Error! Reference source not found.. OL also promotes deeper levels of learning Error! Reference source not found.. Class satisfaction refers to the emotional and cognitive responses of students who participate in the classes Error! Reference source not found. Class satisfaction has been recognized as a strong determinant to evaluate the effectiveness of online classes and is considered a representative

Article history:

Received (December 24, 2020), Review Result (January 24, 2021), Accepted (March 8, 2021) 
variable to improve the academic performance of online classes Error! Reference source not found.. The acquisition of self-directed learning skills is a topic that draws attention not only in the face-to-face learning environment but also in the online learning environment Error! Reference source not found.. Self-directed learning ability refers to the ability of learners to establish and implement learning plans on their own and to evaluate the results systematically and take the initiative in managing the learning process to ensure successful learning outcomes Error! Reference source not found.. Self-directed learning habits are also reportedly formed during online classes Error! Reference source not found.. For successful online learning, learner immersion is important Error! Reference source not found.. In the case of learning immersion, it promotes a high level of concentration and the active participation of learners, so when learners experience immersion in the learning process, the learning process itself becomes enjoyable and they experience satisfaction and fulfillment by actively participating in the classes Error! Reference source not found.. The role of professors who lead, facilitate, and interact over the course of the online class, where contact opportunities between learning participants are limited, is pivotal Error! Reference source not found..

Thus, this study is intended to provide basic data needed to establish an effective learning satisfaction arbitration strategy for nursing students in online classes.

\section{Methods}

\subsection{Study design}

This study is a cross-sectional descriptive survey that examined the correlations between nursing college students' self-directed learning strategies, learning flow, teaching presence, and learning satisfaction. This study identifies factors that affect learning satisfaction in nursing college students.

\subsection{Setting and samples}

The study sample consisted of 110 fourth-grade students attending the department of nursing in G-city, Korea. The subjects of the study were selected by convenience sampling and volunteered to participate. The number of samples in this study was appropriate.

\subsection{Research tools}

\subsubsection{Self-directed learning strategy}

Self-directed learning strategy was measured using the tool modified by Jo Error! Reference source not found. by referring to the tool by Lee Error! Reference source not found. and Ku Error! Reference source not found.. It consisted of seven questions This tool uses a five-point scale ranging from 1 (strongly disagree) to 5 (strongly agree). A Higher score indicated a high level of self-directed learning strategy. The Cronbach's alpha was .76 in the study of Jo Error! Reference source not found. and for the current study it was .77.

\subsubsection{Learning flow}

Learning flow was measured using a tool modified by Yoon Error! Reference source not found. who added questions about the common sense of control presented by Csikszentmihalyi Error! Reference source not found., Hoffman and Novak Error! Reference source not found., and Kim and Byun Error! Reference source not found.. 
It consisted of five questions. This tool uses a five-point scale ranging from 1 (strongly disagree) to 5 (strongly agree). A Higher score indicated a high level of learning flow. The Cronbach's alpha was .83 in the study of Yoon Error! Reference source not found. and for the current study it was .82 .

\subsubsection{Teaching presence}

Teaching presence was measured using the tool developed by Koh Error! Reference source not found.. It consisted of twenty-eight questions. This tool uses a five-point scale ranging from 1 (strongly disagree) to 5 (strongly agree). A Higher score indicated a high level of teaching presence. The Cronbach's alpha was .91 in the study of Koh Error! Reference source not found. and for the current study was .96.

\subsubsection{Learning satisfaction}

Learning satisfaction was measured using the tool developed by Shin and Chan Error! Reference source not found.. It consisted of six questions. This tool uses a five-point scale ranging from 1 (strongly disagree) to 5 (strongly agree). A Higher score indicated a high level of learning satisfaction. The Cronbach's alpha was .84 in the study of Shin and Chan Error! Reference source not found. and for the current study it was .97.

\subsection{Data collection}

Data were collected from May 5 to May 30, 2020 after obtaining approval from the institution. A self-report questionnaire created in Google Forms was used to collect the data. The questionnaire was structured so that questions could only be answered if the participants gave their informed consent after reading the purpose of the study, assurance of the anonymity and confidentiality of the participants, and the possibility of withdrawal from the research. They were assured that the information obtained would be kept confidential. The time needed to respond to all the questions was about 10-15 minutes.

\subsection{Data analysis}

Data were coded and analyzed using SPSS version 25.0 (IBM SPSS Statistics, Chicago, IL, USA). The differences between self-directed learning strategy, learning flow, teaching presence, and learning satisfaction according to demographic characteristics were analyzed using independent sample $t$ tests. The levels of self-directed learning strategy, learning flow, teaching presence, and learning satisfaction were analyzed and expressed as means and standard deviations. To identify the relationships between self-directed learning strategy, learning flow, teaching presence and learning satisfaction, Pearson's correlation was used. Stepwise multiple regression analyses were conducted to determine the factors affecting learning satisfaction.

\section{Results}

\subsection{Level of self-directed learning strategy, learning flow, teaching presence, and learning satisfaction}

The participants' self-directed learning strategy, learning flow, teaching presence, and learning satisfaction were $4.08 \pm 0.56$ (range, 1-5), $3.28 \pm 0.74$ (range, 1-5), $4.15 \pm 0.64$ (range, $1-5$ ), and $4.18 \pm 0.75$ (range, 1-5), respectively Error! Reference source not found.. 
Table 1. Level of self-directed learning strategy, learning flow, teaching presence, and learn satisfaction $(\mathrm{N}=110)$

\begin{tabular}{|c|c|c|c|c|}
\hline Variables & $\mathrm{M} \pm \mathrm{SD}$ & Mini & Max & Range \\
\hline $\begin{array}{c}\text { Self-directed learning } \\
\text { strategy }\end{array}$ & $4.08 \pm 0.56$ & 2.43 & 5.00 & $1-5$ \\
\hline Learning flow & $3.58 \pm 0.74$ & 1.40 & 5.00 & $1-5$ \\
\hline Teaching presence & $4.15 \pm 0.64$ & 2.41 & 5.00 & $1-5$ \\
\hline Learning satisfaction & $4.18 \pm 0.75$ & 2.00 & 5.00 & $1-5$ \\
\hline
\end{tabular}

3.2. Differences in directed learning strategy, learning flow, teaching presence and learning satisfaction by general characteristics

The participants' self-directed learning strategy, learning flow, teaching presence, and learning satisfaction showed not significant statistical differences based on their general characteristics respectively Error! Reference source not found.

Table 2. Differences in self-directed learning strategy, learning flow, teaching presence, and learn satisfaction by general characteristics $(\mathrm{N}=110)$

\begin{tabular}{|c|c|c|c|c|c|c|c|c|c|c|}
\hline \multirow{2}{*}{ Characteristics } & \multirow{2}{*}{ Categories } & \multirow{2}{*}{$\mathrm{N}(\%)$} & \multicolumn{2}{|c|}{$\begin{array}{c}\text { Self-directed } \\
\text { learning strategy }\end{array}$} & \multicolumn{2}{|c|}{ Learning flow } & \multicolumn{2}{|c|}{ Teaching presence } & \multicolumn{2}{|c|}{ Learning satisfaction } \\
\hline & & & $\mathrm{M} \pm \mathrm{SD}$ & $\mathrm{t}(p)$ & $\mathrm{M} \pm \mathrm{SD}$ & $\mathrm{t}(p)$ & $\mathrm{M} \pm \mathrm{SD}$ & $\mathrm{t}(p)$ & $\mathrm{M} \pm \mathrm{SD}$ & $\mathrm{t}(p)$ \\
\hline \multirow[t]{2}{*}{ Gender } & Female & $95(86.4)$ & $4.06 \pm 0.57$ & \multirow[t]{2}{*}{$-0.57(.569)$} & $3.54 \pm 0.72$ & \multirow[t]{2}{*}{$-1.39(.167)$} & $4.13 \pm 0.64$ & \multirow[t]{2}{*}{$-0.96(.340)$} & $4.14 \pm 0.74$ & \multirow[t]{2}{*}{$-1.59(.115)$} \\
\hline & Male & $15(13.6)$ & $4.15 \pm 0.49$ & & $3.83 \pm 0.87$ & & $4.30 \pm 0.61$ & & $4.47 \pm 0.81$ & \\
\hline \multirow[t]{2}{*}{ Age (yr) } & $<29$ & $93(84.5)$ & $4.07 \pm 0.54$ & \multirow[t]{2}{*}{$-0.20(.839)$} & $3.55 \pm 0.74$ & \multirow[t]{2}{*}{$-0.90(.369)$} & $4.16 \pm 0.63$ & \multirow[t]{2}{*}{$0.25(.807)$} & $4.19 \pm 0.76$ & \multirow[t]{2}{*}{$0.87(.704)$} \\
\hline & $\geq 30$ & $17(15.5)$ & $4.10 \pm 0.70$ & & $3.73 \pm 0.77$ & & $4.12 \pm 0.68$ & & $4.12 \pm 0.74$ & \\
\hline
\end{tabular}

\subsection{Correlations between self-directed learning strategy, learning flow, teaching presence and learning satisfaction}

The self-directed learning strategy was positively correlated with learning flow ( $\mathrm{r}=.69$, $p<.001)$, teaching presence $(\mathrm{r}=.59, p<.001)$, and learning satisfaction $(\mathrm{r}=.55, p<.001)$. Learning flow was correlated with teaching presence $(\mathrm{r}=.64, p<.001)$ and learning satisfaction $(\mathrm{r}=.62$, $p<.001)$. Teaching presence was correlated with learning satisfaction $(\mathrm{r}=.86, p<.001)$ respectively Error! Reference source not found.

Table 3. Correlations between self-directed learning strategy, learning flow, teaching presence, and learn satisfaction $(\mathrm{N}=110)$

\begin{tabular}{|c|c|c|c|c|}
\hline \multirow{2}{*}{ Variables } & $\begin{array}{c}\text { Self-directed learning } \\
\text { strategy }\end{array}$ & Learning flow & Teaching presence & $\begin{array}{c}\text { Learning } \\
\text { satisfaction }\end{array}$ \\
\cline { 2 - 5 } & \multicolumn{4}{|c|}{$\mathrm{r}(p)$} \\
\hline $\begin{array}{c}\text { Self-directed learning } \\
\text { strategy }\end{array}$ & 1 & 1 & & \\
\hline Learning flow & $.69(<.001)$ & $.64(<.001)$ & 1 & 1 \\
\hline Teaching presence & $.59(<.001)$ & $.62(<.001)$ & $.86(<.001)$ & \\
\hline Learning satisfaction & $.55(<.001)$ & & & \\
\hline
\end{tabular}

\subsection{Factors influencing learning satisfaction}


To investigate the factors influencing learning satisfaction, a stepwise multiple regression analysis was conducted including three variables (learning flow, teaching presence, and learning satisfaction). As a result of checking autocorrelation with Durbin-Watson statistic, the assumption of residual independence was fulfilled as it was close to 2 (1.698). As a result of the test of multicollinearity using the tolerance limit and the variation inflation factor (VIF) value, it was found that all variables did not have multicollinearity problem because the tolerance limit was .10 or higher or the VIF value was not more than 10 (tolerance limit: 1.00, VIF: 1.00), and the condition index was less than 30. According to these statistics, there was no problem of multicollinearity. This analysis confirmed that the data met the assumptions of residuals, linearity, normality, and homoscedasticity of error terms. Results of stepwise multiple regression analysis showed that teaching presence $(\mathrm{F}=305.51, p<.001)$ were main factors affecting learning satisfaction in nursing college students. Regression analysis revealed that the explanatory power of this regression model was approximately $74.0 \%$ Error! Reference source not found..

Table 4. Factors influencing learning satisfaction $(\mathrm{N}=110)$

\begin{tabular}{|c|c|c|c|c|c|}
\hline Variables & B & S.E & $\beta$ & $\mathrm{t}$ & $p$ \\
\hline (constant) & -.01 & .24 & & -.05 & .961 \\
\hline Teaching presence & 1.01 & .06 & .86 & 17.48 & $<.001$ \\
\hline \multicolumn{7}{|c|}{$\mathrm{R}^{2}=.74$, Adj. $\mathrm{R}^{2}=.74, \mathrm{~F}=305.51(p<.001)$} \\
\hline
\end{tabular}

\section{Discussion}

By identifying the self-directed learning strategies, learning flow, and learning satisfaction of nursing students and identifying the factors influencing their learning satisfaction, the study attempted to use them as basic data needed to establish an effective learning satisfaction arbitration strategy for nursing students in online classes.

The participants' mean score for self-directed learning strategy was 4.08 points out of 5 . The results of this study were similar to those of Jeon and Yoo Error! Reference source not found., who scored 4.49 out of 6 in self-directed strategies. However, the results of this study higher those of Park Error! Reference source not found., who scored 3.45 out of 5 in self-directed learning ability general university students. In this study, the participants' mean score for learning flow was 3.58 points out of 5 . The results of this study were similar to those of Lee, Kim, and Lee Error! Reference source not found., whose immersion in learning score was 3.27 out of 5 for nursing college students who experienced online lectures. In addition, the immersion of medical students in the online learning environment was similar to that of Jeon and Yoo Error! Reference source not found., who scored 4.03 out of 6points. The results of this study were higher than the mean 2.84 points of Jeong and Han's study Error! Reference source not found. It is thought that this difference occurred because the subjects of this study were fourth-grade students and the study by Jeong and Han Error! Reference source not found. included all grades. Research is needed to compare learning flow in face-to-face and non-face-to-face classes on the same subject. In this study, the participants' mean score for teaching presence was 4.15 points out of 5 . The result of teaching presence was higher than the mean of 3.11 points of Lee's study Error! Reference source not found.. The difference is likely to depend on how much professors intervene in the class. The researcher was required to notify the class through representatives of the contents of the class, the duration of the class, 
etc. The researchers also checked the learning weekly to encourage learning through text messaging and to create an atmosphere where questions could be answered freely. Therefore, it is believed that the subjects of this study were highly aware of the actuality of teaching. In this study, the participants' mean score for learning satisfaction was 4.38 points out of 5 . The results of this study were higher than those of Jeon and Yoo Error! Reference source not found., whose satisfaction with learning score was 4.38 out of 6 . These differences are seen as the difference between the subject of study and methods of teaching used by professors. It is believed that the subjects of this study were also able to express high levels of satisfaction with the online classes as the pandemic made the situation inevitable.

With regard to the correlations between self-directed learning strategy, learning flow, teaching presence, and learning satisfaction, the results of this study were consistent with those of Chon and Yoo's study Error! Reference source not found., which confirmed that immersion increases if nursing college students have a high level of self-directed learning strategy. The results of this study were also in agreement with the results of Lee's study Error!

Reference source not found., which found that the higher the degree of teaching presence for online learners, the higher the flow in learning. The results of this study were similar to those of Yoo Error! Reference source not found., which found that the higher the interaction between professors and learners, the higher the satisfaction level in the class. Hence, all these results strongly suggest that it is necessary to establish a self-directed learning strategy, learning flow, and strategies to enhance teaching presence in order to improve learning satisfaction in nursing students. However, since most of the studies focus on college students taking face-toface classes and measurement tools and content vary from study to study, it is difficult to compare and interpret the results with nursing college students. Therefore, more in-depth follow-up studies are needed that consider the characteristics of nursing college students in online learning.

In this study, the impact factor on learning satisfaction among nursing college students was found to be teaching presence. Of the learners, $29.3 \%$ appeared to have difficulty interacting with professors because of their satisfaction with the implementation and evaluation of fullscale online classes in college under COVID-19 circumstances Error! Reference source not found.. Class-action studies to satisfy online class learners showed that they participated in the class with self-reliance, motivating research through interaction and feedback with professors Error! Reference source not found. The independent influence on learning satisfaction was shown to be the greatest social reality for professors Error! Reference source not found.. Various research results show that the role of professors in online learning is important. To improve learning satisfaction, interventions are needed to enable professor-student interactions to occur efficiently Error! Reference source not found.. Therefore, in order to improve learning satisfaction in online classes, this study found that it is necessary to find and apply various ways to increase the level of teaching presence.

\section{Conclusions}

This study aimed to examine factors that influence learning satisfaction in nursing college students. The factor influencing the learning satisfaction of nursing students in this study was teaching presence. It suggested that the role of professors in online learning is important. Therefore, in order to improve the learning satisfaction of nursing college students in online classes, a variety of methods should be explored and applied to enhance teaching presence.

There are some limitations to our study. In this study were selected by convenience sampling of fourth-grade students attending the department of nursing in a region of Korea. 
Therefore, the generalizability of the sample could be limited. Based on the above results, I would like to suggest the following. First, since this study was conducted on nursing college students, repeated studies on more local nursing college students are needed to ensure the generalization and validity of the study. Second, research is needed to develop teaching learning strategies and verify the effectiveness of online classes for nursing students to improve online classes.

\section{References}

[1] A. Luyben, V. Fleming, and J. Vermeulen, "Midwifery education in COVID-19-time: Challenges and opportunities,” Midwifery, vol.89, (2020) DOI: 10.1016/j.midw.2020.102776

[2] V. Singh and A. Thurman, "How many ways can we define online learning? A systematic literature review of definitions of online learning (1988-2018)," American Journal of Distance Education, vol.33, no.4, pp.289-306, (2019)

[3] L. Webb, J. Clough, D. O'Reilly, D. Wilmott, and G. Witham, "The utility and impact of information communication technology (ICT) for pre-registration nurse education: A narrative synthesis systematic review," Nurse Education Today, vol.48, pp.160-171, (2017) DOI: 10.1016/j.nedt.2016.10.007

[4] S. K. Shim, "Relationship among the learning instrument, learning achievement, and learning satisfaction in online class," Journal of the Korea contents association, vol.12, no.3, pp.487-497, (2012) DOI: 10.5392/JKCA.2012.12.03.487

[5] M. Kurucay and F. A. Inan, "Examining the effects of learner-learner interaction satisfaction and learning in an online undergraduate course," Computers and Education, (2017), vol.115, pp.20-37

[6] Y. J. Chae, S. H. Lee and S. H. Park, "Analysis of the perception of effectiveness and satisfaction according to learners' background variables and characteristics in online gifted education program," Journal of Gifted/Talented Education, vol.26, no.4, pp.611-633, (2016) DOI: 10.9722/JGTE.2016.26.4.611

[7] S. J. Lee, Y. K. Chang, H. N. Lee, and K. Y. Park, "A study on the development of life-skills: Communication, problem solving, and self-directed learning," Seoul: Korean Education Development Institute, Report No.: RR 2003-15-3, (2003)

[8] H. G. Jung, "College students' satisfaction with the overall implementation of online classes and testing during the corona 19 pandemic," Multimedia-Assisted Language Learning, vol.23, no.3, pp.392-412, (2020) DOI: 10.15702/mall.2020.23.3.392

[9] J. Webster and P. Hackley, "Teaching effectiveness in technology-mediated distance learning," Academy of Management Journal, vol.40, no.6, pp.1282-1309, (2017) DOI: 10.5465/257034

[10] S. I. Park and Y. K. Kim, "An inquiry on the relationships among learning-flow factors, flow level, achievement under on-line learning environment," The Journal of Yeolin Education, vol.14, no.1, pp.93-115, (2006)

[11] E. K. Lee and Y. J. Kim, "Differences in the social presence of instructor by instructor's social intervention and its effects on learning satisfaction in an online university," The Journal of Korean association of computer education, vol.18, no.3, pp.69-78, (2015)

[12] S. A. Jo, "The influence of university students' online course experience and level of self-directed learning strategy on learning satisfaction and persistence," M.S. Thesis, Korea National University of Education, Cheongju, (2013)

[13] I. S. Lee, "Relationships between e-learning strategies and learning achievement," Journal of Educational Technology, vol.18, no.2, pp.51-67, (2002)

[14] G. J. Ku, "A study on factors associated with the effectiveness of distance adult education: The case of distance information education for teachers," Ph.D. dissertation, Hongik University, Seoul, (2006)

[15] S. I. Yoon, "Verification of the predictability of learners' motivation, teaching presence, learning flow on learning outcome in cyber university," M.S. Thesis, Ewha Womans University, Seoul, (2013)

[16] M. Csikszentimihalyi, "Beyond boredom and anxiety,” Jossey Bass, San Francisco, (1975) 
[17] D. L. Hoffman and D. L. Novak, "Marketing in hypermedia computer-mediated environments: Conceptual foundation," Journal of Marketing, vol.60, no.3, pp.50-69, (1996)

[18] J. H. Kim and H. S. Byun, "The role of cognitive absorption as a mediating variable in virtual community," Information Systems Review, vol.6, no.2, pp.47-63, (2004)

[19] E. H. Koh, "Development of a teaching presence scale in e-learning environments," Ph.D. dissertation, Korea Universtiy, Seoul, (2007)

[20] N. M. Shin and J. Chan, "Direct and indirect effects of online learning on distance education," British Journal of Educational Technology, vol.35, no.3, pp.275-288, (2004)

[21] S. J. Jeon and H. H. Yoo, "Relationship between general characteristics, learning flow, self-directedness and learner satisfaction of medical students in online learning environment," Journal of the Korea contents association, vol.20, no.8, pp.65-74, (2020) DOI: 10.5392/JKCA.2020.08.065

[22] J. Y. Park, “The effects of university students' self-directed learning ability and perceived online task value on learning satisfaction and academic achievement," English Language Teaching, vol.29, no.3, pp.165-185, (2017) DOI: 10.17936/pkelt.2017.29.3.8

[23] J. G. Lee, W. J. Kim and J. K. Lee, "The relationship between learning motivation, learning commitment and academic achievement of nursing students who gave non-face-to-face online lectures," Journal of the Korea Academia-Industrial Cooperation Society, vol.21, no.11, pp.412-419, (2020) DOI: 10.5762/KAIS.2020.21.11.412

[24] S. E. Jeong and J. H. Han, "The influence of personality characteristics, self-leadership and positive psychological capital on learning flow of nursing students," The Journal of Korean Academic Society of Nursing Education, vol.25, no.4, pp.393-404, (2019) DOI: 10.5977/jkasne.2019.25.4.393

[25] S. H. Lee, "The effects of teaching presence on students' learning flow and academic achievement in online education of universities," Journal of Hotel \& Resort, vol.19, no.5, pp.227-246, (2020)

[26] J. E. Yoo, "Structural relationship among self-directed learning ability, learner-instructor interaction, learnerlearner interaction, and class satisfaction in online learning environments," Journal of Christian Education in Korea, vol.63, pp.255-281, (2020) DOI: 10.17968/jcek.2020.63.009

[27] S. J. Park and S. H. Chae, "Study on teaching performance for satisfaction of online class learner of C university graduate school of education due to COVID-19," Journal of Learner-Centered Curriculum and Instruction, vol.20, no.20, pp.1319-1344, (2020) DOI: 10.22251/jlcci.2020.20.20.1319

[28] M. K. Cho and M. Y. Kim, "Effects of self-directed learning readiness, teacher-student interaction, and academic achievement on core competency, learner motivation, and learner satisfaction in nursing students," Journal of the Korea Academia-Industrial cooperation Society, vol.19, no.3, pp.161-170, (2018) DOI: 10.5762/KAIS.2018.19.3.161 